\title{
A crítica de Marx ao conceito de cidadania
}

\author{
Marx's critique of the concept of citizenship
}

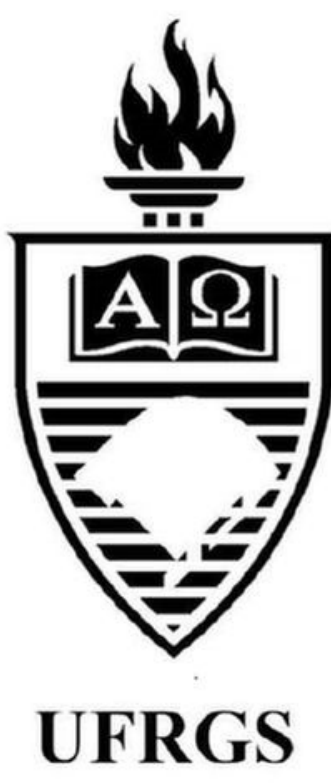

\section{Rose Dayanne Santos de Brito}

Università degli Studi di Roma Tor Vergata 


\title{
A crítica de Marx ao conceito de cidadania
}

\author{
Marx's critique of the concept of citizenship
}

Rose Dayanne Santos de Brito*

\section{REFERÊNCIA}

BRITO, Rose Dayanne Santos de. A crítica de Marx ao conceito de cidadania. Revista da Faculdade de Direito da UFRGS, Porto Alegre, n. 39, vol. esp., p. 129-140, dez. 2018.

\section{RESUMO}

O objetivo do presente artigo é identificar a crítica de Marx ao conceito moderno de cidadania. A hipótese principal é que os fundamentos da crítica de Marx ao direito e a cidadania permanecem válidas na pós-modernidade. Até porque a disparidade ontológica entre capital e trabalho persiste no capitalismo financeiro.

\section{PALAVRAS-CHAVE}

Cidadania. Crítica do direito. Marx.

\section{ABSTRACT}

The purpose of this paper is to identify Marx's critique of the modern concept of citizenship. The main hypothesis is that the fundamentals of Marx's critique of law and citizenship remain valid in postmodernity. This is because the ontological disparity between capital and labor persists in financial capitalism.

\section{KEYWORDS}

Citizenship. Criticism of law. Marx.

\section{SUMÁRIO}

Introdução. 1. Do conceito liberal de cidadania à crítica marxiana. 2. Marx e a Questão judaica. 3. Cidadania, neoliberalismo e pós-modernidade. 3.1. A colonialidade brasileira e a dialética de Lyra Filho. Conclusão. Referências.

\section{INTRODUÇÃO}

$\mathrm{O}$ artigo situa o contexto histórico do conceito jurídico-político de cidadania. A matriz ideológica da formação dos Estados liberais e a defesa de uma igualdade formal aparecem na obra clássica "Cidadania, classe social e status" de Thomas Humprey Marshall, publicada em 1950.

A contraposição ao trabalho alienado e as ambiguidades ontológicas do direito fundamentam a crítica de Karl Marx no século XIX. No texto "Sobre a Questão Judaica", Marx questiona o tratamento jurídico às questões reais e materiais, as desigualdades na sociedade capitalista. $\mathrm{O}$ cidadão abstrato repleto de direitos e protegido na Declaração de Direitos do Homem e do Cidadão (1789) e, ainda hoje, nas Cartas Constitucionais não passa de um ente metafísico, que na prática não verifica a plenitude de seus direitos.

A Constituição brasileira de 1988 assegura no seu art. $1^{\circ}$ a cidadania como fundamento do Estado democrático de direito. O que significa isso na práxis social? Por sua vez, a Constituição italiana de 1948 , em seu art. $4^{\circ}$ reconhece aos cidadãos o direito ao trabalho e as condições que tornem efetivo esse direito ${ }^{1}$. Quantos jovens italianos estão desempregados ou se submetem à precarização do mercado de trabalho?

\footnotetext{
* Doutoranda em Direito pela Università degli Studi di Roma Tor Vergata, Itália. Mestra em Direito pela Universidade Federal de Santa Catarina. Graduada em Direito na Universidade Federal de Pernambuco, com período cursado na Alemanha (Eberhard Karls Universität Tübingen).

1 “Art. 4. La Repubblica riconosce a tutti i cittadini il diritto al lavoro e promuove le condizioni che rendano effettivo questo diritto. Ogni cittadino ha il dovere di svolgere, secondo le proprie possibilità e la propria scelta, una attività o una funzione che concorra al progresso materiale o spirituale della società."
} 
O conceito de cidadania é um pilar do direito e do Estado moderno e continua nuclear na sociedade do século XXI. Sobretudo, nos períodos eleitorais, em que o cidadão manifesta um status de participação na vida política do país. Porém, quais as contradições implícitas neste conceito? Há uma continuidade histórica ou ruptura na noção que permanece hoje?

$\mathrm{O}$ artigo busca, portanto, demonstrar que a crítica de Karl Marx permanece viva. Para comprovar esta hipótese, o estudo é feito em torno do conceito de cidadania e seus desdobramentos na estrutura do capitalismo financeiro. O intuito é verificar "a inserção do direito no seio do projeto jurídico liberal, instrumentalizando-o de forma tão lúcida e inflexível, algo que tem comprometido a autonomia do jurídico e tem dissecado seus nexos naturais com a sociedade e com a história" (GROSSI, 2005, p. 36).

\section{DO CONCEITO LIBERAL DE CIDADANIA À CRÍTICA MARXIANA}

Um ponto de partida no estudo do conceito de cidadania é a referência à obra clássica do sociólogo inglês Thomas Humprey Marshall, "Cidadania, classe social e status", publicada em 1950. Pode-se dizer que Marshall elaborou "uma concepção liberal-democrática ampliada de cidadania, que estendeu o status de cidadão a novos atores e a outros antes discriminados. Sua leitura evolucionista identifica no contexto inglês, uma ampliação do raio de abrangência do conceito de cidadania" (BELLO, 2013, p.63).

$\mathrm{Na}$ tentativa de desenvolver as promessas não cumpridas do discurso moderno de cidadania, Marshall introduz no debate a questão das classes sociais. Por um lado, ele desloca o conceito de cidadania, vinculado à ideia abstrata de igualdade formal, para o prisma das desigualdades sociais. Nesse sentido, tem muitas virtudes a obra do sociólogo, inclusive pela possibilidade de "despertar os juristas do sono dogmático" através da aproximação empírica com as estruturais sociais. Por outro lado, fica preso na matriz jurídica do conceito, ao reduzir cidadania à titularidade de direitos e a linearidade histórica, na medida em que propõe "dividir o conceito de cidadania em três partes [...] civil, política e social." (MARSHALL, 1967, p. 63).

Para ele, houve uma expansão do conceito de cidadania com os direitos civis na luta pela liberdade individual no século XVIII; na inclusão do elemento político com as reivindicações do século XIX (reduz o aspecto político à ampliação do direito de voto); e pelo mínimo de bem-estar econômico-social garantido no século XX. Essa periodização influenciou toda uma geração de juristas, inclusive, os brasileiros a partir de 1970.

A concepção marshalliana, porém, não questiona as disparidades ontológicas da sociedade capitalista (capital $\mathrm{x}$ trabalho) apenas propõe uma equalização do status jurídicopolítico dos cidadãos pela via institucionalizada do Estado. Até porque, de acordo com ele, "a igualação não se refere tanto a classes [...] a igualdade de status é mais importante do que a igualdade de renda" (MARSHALL, 1967, p. 9495).

Esta concepção de cidadania é particular por ter como pano de fundo a Inglaterra do século $\mathrm{XX}$, porém é universalista ao construir um modelo de cidadão analogamente ao "leito de procusto". Dessa leitura, depreende-se a reflexão de que "houve aliás um tempo, nem longínquo nem terminado, em que nós os homens 'queria dizer' nós os europeus adultos machos brancos carnívoros e capazes de sacrifícios" (DERRIDA, 2010, p. 34). Nas conclusões do livro, Marshall traz dois resultados importantes, porém refutáveis.

A primeira tese defende a "educação como um meio de dar [ao estudante] algo cujo valor poderia aproveitar ao máximo, qualquer que fosse sua posição na vida profissional" (MARSHALL, 1967, p. 100) e, na segunda tese, propõe o 
equilíbrio entre direitos e deveres enfatizando a "importância fundamental do dever de trabalhar" (MARSHALL, 1967, p. 109).

É necessário destacar que a inclusão das classes sociais no debate da cidadania não fez Marshall criticar a própria estrutura desigual do capitalismo. Se, por um lado, ele exalta o dever de trabalhar, por outro ele despreza a própria dialética do trabalho (riqueza e miséria). Esta contradição já havia sido anunciada um século antes, seguindo a verificação de que "o trabalhador se torna tanto mais pobre quanto mais riqueza produz, quanto mais a sua produção aumenta em poder e extensão. $\mathrm{O}$ trabalhador se torna uma mercadoria tão mais barata quanto mais mercadorias cria" (MARX, 2004, p. 80).

Para o sociólogo britânico, o fundamento da cidadania é a aquisição de direitos e o cumprimento de deveres. A exaltação do "dever de trabalhar" é uma decorrência do posicionamento ideológico do autor, pois defende a garantia formal dos direitos dos trabalhadores, mas não indica a possibilidade de os cidadãos promoverem a ruptura do sistema de desigualdades sociais.

Nesse sentido, Marshall se afasta, por exemplo, das pesquisas realizadas por Engels, no século XIX, publicada no livro "A situação da classe trabalhadora na Inglaterra" (1845). Em que defende que "a situação da classe operária é a base real e o ponto de partida de todos os movimentos sociais de nosso tempo porque ela é, simultaneamente, a expressão máxima e a mais visível manifestação de nossa miséria social" (ENGELS, 2008, p. 41).

Ainda na questão do "dever do trabalho", Marshall omite os espectros marxistas de Paul Lafargue e sua conhecida obra "Direito a Preguiça", publicada 1880, na qual acredita que “nossa época [século XIX] é, dizem, o século do trabalho; de fato é o século da dor, da miséria e de corrupção" (LAFARGUE, 2003, p. 14). Nota-se, que a interpretação de Marshall sobre o trabalho é bastante diversa da tradição marxiana, porém se aproxima muito do pensamento burguês de Adam Smith e David Ricardo que unilateralmente via o trabalho como fonte de riqueza.

Nessa perspectiva, o modelo de cidadão fabricado é o trabalhador que tem suas horas roubadas pela mais-valia, que paga assiduamente os impostos e têm suas vidas manipuladas pela mão invisível do mercado.

Marshall contribuiu para o debate sobre a cidadania inserindo a questão das classes sociais, mas se limitou ao aparato institucional, diante disso busca-se apresentar outros giros teóricos sobre o conceito de cidadania. A hipótese deste artigo é problematizar o "véu jurídico" do conceito de cidadania para interpretar criticamente o trabalho alienado, a educação e a exclusão social. Compreende-se que o discurso da cidadania é a muralha jurídica da modernidade, o fator de legitimação da burguesia para obter o poder político, logo explorar as ambiguidades deste conceito possibilita questionar os limites e mitos da modernidade.

Ademais, a própria periodização histórica da cidadania é um engodo, uma vez que "esses direitos não são substituídos ou alterados de tempos em tempos, de forma unilateral e sequencial, mas resultam num processo material de lutas sociais, fazendo-a e complementando-se. Tampouco possuem um conteúdo abstrato, único e permanente" (WOLKMER, 2012, p. 21).

Existem vários trabalhos de "análise crítica da concepção marshalliana, especialmente os de Anthony Giddens, David Held e Danilo Zolo no Exterior, e José Murilo de Carvalho e José Maurício Domingues no Brasil”" (BELLO, 2013, p. 64). Com o intuito de não restringir apenas ao debate pós-marshall, propõe-se demonstrar as fissuras do discurso da cidadania baseado no método histórico-dialético. Por isso, voltamos a Marx. Para compreender a cidadania à luz da luta de classes. A escolha deste marco teórico é justificada pelo fato de que "o marxismo é a 
filosofia insuperável do nosso tempo. Ele é insuperável porque as circunstâncias que o engendram não foram superadas" (SARTRE, 1972, p. 25).

\section{MARX E A QUESTÃO JUDAICA}

No ano de 1843, o jovem Marx publica o "Manuscrito de Kreuznach" conhecido como "Crítica da filosofia do direito de Hegel". Neste texto, são apresentados apontamentos críticos à teoria política do Estado e aos filósofos idealistas da Revolução Francesa. Pode-se dizer que a crítica central de Marx "à filosofia política de Hegel é o da separação e oposição modernas entre Estado e sociedade civil e a tentativa hegeliana de conciliar esses extremos na esfera do Estado" (MARX, 2005, p. 18).

Enquanto Hegel enfatiza a figura do Estado como um símbolo da libertação dos indivíduos, Marx aponta o antagonismo de classe e as contradições da constituição política do Estado Moderno. Esse conteúdo é desenvolvido no texto "Sobre a Questão Judaica", concluído no mesmo ano. Encontra-se nesta obra uma crítica aos "direitos humanos, engendrados pelas Declarações burguês-individualistas do século XVIII, [identificadas nas] contradições entre os direitos do homem burguês (sociedade civil) e os direitos do cidadão abstrato (Estado político)" (WOLKMER, 2004, p.26).

Marx, nessas duas obras, questiona os fundamentos da modernidade indagando sobre o que haveria mudado historicamente para os homens ganharem o status de cidadãos do Estado (Staatsbürger)? Em outras palavras, quais seriam os pressupostos da distinção entre o homem individual e o cidadão abstrato? $\mathrm{Na}$ questão judaica, Marx contrapõe as teses do hegeliano Bruno Bauer e argumenta que:

[...] a realização plena do idealismo do Estado representou concomitantemente a realização plena do materialismo da sociedade burguesa. $\mathrm{O}$ ato de sacudir de si o jugo político representou concomitantemente sacudir de si as amarras que prendiam o espírito egoísta da sociedade burguesa. $A$ emancipação política representou concomitantemente a emancipação da sociedade burguesa em relação à política, até em relação à aparência de um teor universal. A sociedade feudal foi dissolvida em seu fundamento, no homem, só que no tipo de homem que realmente constituía esse fundamento, no homem egoísta. Esse homem, o membro da sociedade burguesa, passa a ser a base, o pressuposto do Estado politico. Este o reconhece como tal nos direitos humanos (2010, p.52, grifo nosso).

Nessa linha de raciocínio, a emancipação política equivale à conquista do poder político pela burguesia. $\mathrm{O}$ homem egoísta torna-se cidadão através das Declarações formais influenciadas pela Revolução Francesa e, por conseguinte, tem sua propriedade privada $\mathrm{e}$ segurança individual universalizada como garantias jurídicas. Dessa forma, a legitimidade racional-legal foi um importante instrumento de acesso da burguesia à política. Os homens foram reconhecidos juridicamente como cidadãos, livres e iguais. Isso, porém, significava na prática que o servo, agora cidadão, seria "livre" para vender sua força de trabalho a uma minoria detentora dos meios de produção (a burguesia) em troca de um aviltante preço (o salário).

Diante dessa conjuntura, a crítica marxiana indica que "a ficção jurídica e operacional da igualdade e liberdade abstrata dos cidadãos, oculta a realidade concreta das classes sociais profundamente diferenciadas e, não raro, antagônicas em seus interesses" (ALVES, 2002, p. 26).

Após apresentar os limites da emancipação política (os direitos formais), Marx sugere a ruptura das desigualdades sociais através da emancipação humana. É importante esclarecer "que emancipação humana não é um estado, um ponto de chegada, mas um determinado patamar, uma determinada forma de sociabilidade" (TONET, 2005, p. 476). No artigo publicado em 
$1844^{2}$, ele indica a classe responsável pelo processo de transformação social emancipatória.

Essa classe possui "um caráter universal mediante seus sofrimentos universais e não [reivindica] nenhum direito particular porque contra ela não se comete uma injustiça particular, mas a injustiça por excelência, [e não exige] um título histórico, mas apenas o título humano [...]" (MARX, 2005, p. 156). A esse sujeito revolucionário chamou de proletariado.

Segundo Marx, a emancipação da classe operária era o vetor de emancipação das demais esferas de desigualdades sociais. Posteriormente, no livro Grundrisse, desenvolve o tema da alienação jurídica a partir da crítica da economia política; entendendo o direito, portanto, como uma superestrutura da sociedade capitalista. Dessa forma, a classe trabalhadora não deveria se contentar apenas com os chamados "direitos do cidadão".

Na obra magna (O Capital), ele demonstra a impossibilidade de separar as relações econômicas desiguais das outras questões sociais, até por que "as mercadorias não vão ao mercado com seus pés, a relação do direito, que tem o contrato por forma, é uma relação de vontade, em que se reflete uma relação econômica" (MARX, 2008, p. 109).

Diferente de Marshall que abordou o conceito de cidadania pela garantia de direitos às classes sociais, Marx, no século XIX, apontou os problemas da instrumentalização político-jurídico do conceito de cidadania. Não apenas com referência as classes sociais, mas, sobretudo, na luta de classes. Nesse sentido, sua crítica continua atual.

Através do método dialético marxiano é possível concluir que "todos os fenômenos econômicos ou sociais, todas as chamadas leis da economia e sociedade, são produtos da ação humana e, portanto, podem ser transformados [...]

${ }^{2}$ Zur Kritik der Hegelschen Rechtsphilosophie -Einleitung (Crítica da Filosofia do Direito de Hegel- Introdução). pelos próprios indivíduos num processo que pode ser, por exemplo, revolucionário" (LÖWY, 2010, p. 15). Disso decorre a diferença entre a dialética de Hegel e a de Marx, a primeira é conservadora (legitima o Estado burguês) e a segunda é crítica, pois pretende superar a exclusão social pela autoemancipação do oprimido.

$\mathrm{Se}$ o capitalismo possibilitou a internacionalização dos mercados e das pessoas, por outro lado, promoveu uma exploração brutal e desmedida dos seres humanos. A partir de 1970, o capitalismo tornou-se globalizado e as consequências societárias são perceptíveis. Nesse novo contexto, surgem teorias contemporâneas sobre o conceito de cidadania com teor crítico, algumas, de natureza marxista.

\section{CIDADANIA, NEOLIBERALISMO E PÓS- MODERNIDADE}

Nos tópicos anteriores, buscou-se comprovar que "alcançar, pois, a cidadania, não é possuir um status como diz o Marshall: é avançar no estado de consciência social que é o cerne do coletivo" (COELHO, 1990, p. 24). Nesse caminho, as críticas de Marx à engenharia institucional do capitalismo são essenciais para uma interpretação crítica da Modernidade. Entretanto, para compreender as mudanças no aspecto político-econômico e a dialética social do século XXI, novos dados teóricos e empíricos são necessários na atualidade.

É possível ilustrar o "triangulo institucional do capitalismo" 3 através da figura abaixo. No primeiro momento, tem-se o capitalismo competitivo clássico da segunda metade do século XIX, posteriormente a expansão imperialista possibilitou o capitalismo monopolista com o crescimento das empresas. No pós-Segunda Guerra Mundial, o Estado de Bemestar criou medidas protecionistas e assistenciais.

${ }^{3}$ Em= empresas; Es= Estados; $\mathrm{M}=$ mercados. Observar os tamanhos divergentes em cada quadro. 
A partir de 1970 e, principalmente em 80, Margaret Thatcher, na Inglaterra, e Reagan, nos EUA, estabeleceram a política neoliberal, a qual foi disseminada pelo mundo através da globalização aumentando desenfreadamente o índice de pobreza e desigualdade nos países. Uma nova forma de liberalismo, porém mais agressiva.

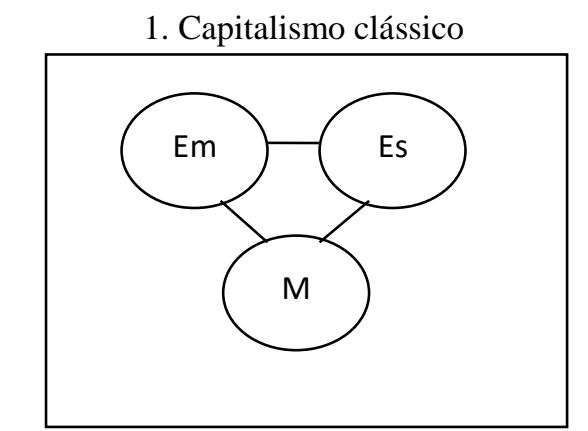

3. Capitalismo no Estado de Bem-Estar

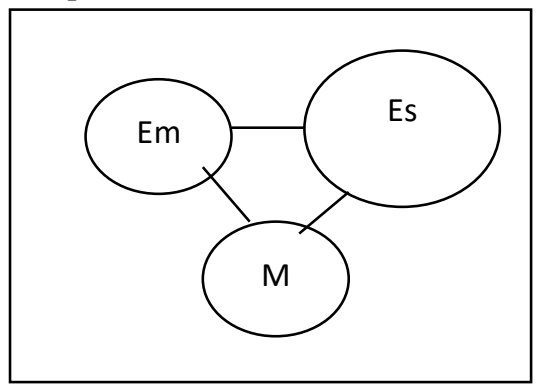

2. Capitalista Monopolista

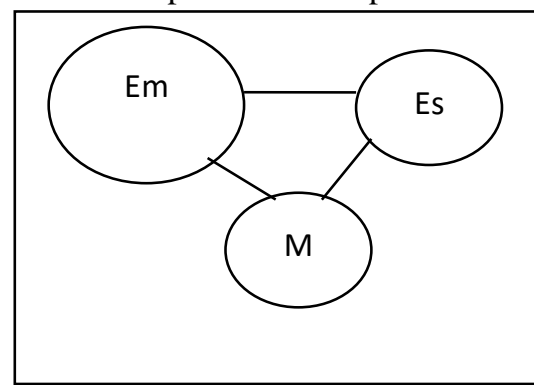

4. Novo Capitalismo

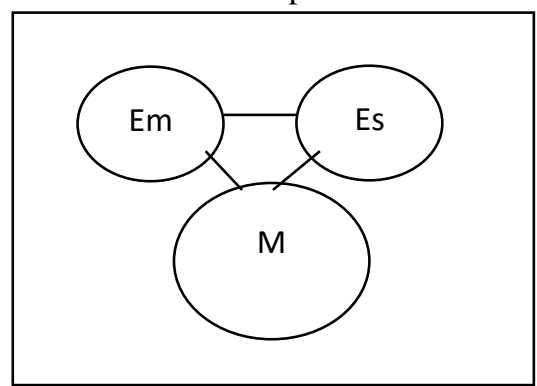

FONTE: THERBORN, 1995, p. 41-42.

As várias formas de manifestação do capitalismo são decorrência das crises cíclicas que ocorreram historicamente. É indispensável explicar que essas crises "não conduzem o capitalismo a seu fim sem a intervenção de massas de milhões de homens e mulheres organizados e dirigidos para a sua destruição mesmo em crise, deixado a si mesmo [o capitalismo] só resulta... mais capitalismo" (NETTO, 2012, p. 415). Da mesma forma, que o capitalismo contemporâneo não é o mesmo do século XIX, a "cidadania não significa mais a mesma coisa que nacionalidade, devido a fatores como imigração, diferentes origens étnicas, particularidades políticas etc" (VIEIRA, 2002, p. 393).

Na conjuntura atual, o conceito de cidadania ganha adjetivos de multicultural, cosmopolita, global, pós-nacional e geralmente aparece envolto pelo discurso dos direitos humanos. O sociólogo português, Boaventura de Sousa Santos, considera que "o projeto da modernidade sacralizou o direito e trivializou os direitos. Temos agora de fazer o trajeto inverso: trivializar o direito e sacralizar os direitos. São necessários cada vez mais eficazes direitos humanos" (1989, p.9). Para ele, os direitos humanos são parte do projeto da modernidade e é sustentado por dois pilares: o pilar da regulação e o pilar da emancipação. O objetivo, na pós-modernidade, seria vincular a regulação à emancipação social e concretizá-la a nível global.

Uma contribuição da leitura de Boaventura é reconhecer que a pergunta se o direito é ou não emancipatório não é significativa, porque emancipatório ou não são os movimentos sociais que conseguem criar novos direitos para além das generalidades abstrata da Lei. $O$ intelectual português, porém, não aponta (no texto publicado em 1989, citado acima) o paradoxo dos direitos humanos que "são, ao mesmo tempo, a criação 
desse primeiro dever ético fundamental e a distorção do imperativo moral, um reconhecimento da singularidade do Outro que, entretanto, revela a necessidade de acomodar muitos" (DOUZINAS, p. 2009, p. 353).

Embora sejam várias as virtudes das obras de Boaventura, faz-se indispensável mencionar o excelente artigo do professor José Paulo Netto intitulado "De como não ler Marx ou o Marx de Sousa Santos". Neste texto, o professor brasileiro afirma que: "é débil e frágil o tratamento teóricocrítico que [Boaventura] conferiu ao objeto [no livro "Pela Mão de Alice"] - do qual resulta uma leitura vulgar e muito simplória da tradição marxista. Resultado não só injustificável, quando se conhece o talento do autor e se reconhece a riqueza do objeto [...]" (NETTO, 2004, p. 230).

Por outro lado, Netto acredita que, dentre os sociólogos "pós-modernos", é respeitável a interpretação de Boaventura sobre o papel revolucionário da classe trabalhadora, pois segundo o intelectual português, "se a transformação social não pode ser feita só com o operariado, tão pouco será feita sem ele ou contra ele" (SANTOS, 1995, p. 272).

Nessa tendência, a compreensão do pensador brasileiro Marildo Menegat avança no debate acerca dos desafios do presente tempo histórico, pois a partir da "afirmação de Marx, de que a humanidade somente se coloca problemas que pode resolver, deve ser posto em toda a sua amplitude, que neste momento histórico significa: ou lutamos pelo socialismo, ou a barbárie se tornará cada vez mais inexorável” (2007, p. 46).

\subsection{A colonialidade brasileira e a dialética de Lyra Filho}

Conforme ficou explícito, o conceito de cidadania é um pilar do Estado Moderno, juntamente à tripartição de poderes e ao mito do contrato social. Nesse sentido, o discurso de cidadania reflete o olhar eurocêntrico sobre a socialidade e as engenharias institucionais. Como o projeto iluminista não realizou as promessas da modernidade nem o tão almejado progresso social, faz-se necessário uma re-leitura do conceito de cidadania a partir do ponto de vista dos "Outros" sujeitos excluídos (do colonizado, do não proprietário, do feminino, do negro, do operariado etc).

Rever o pacto moderno significa "dar voz" aos sujeitos renegados, como também, questionar a gênese excludente do conceito de cidadania. "Hoje, o operário não tira mais o boné fazendo uma reverência ao "sr. dr." que passa fumando charuto e com a mais-valia no bolso. Ele percebeu que existe "algo errado" no sistema [...] (LYRA FILHO, 1999, p. 20). Dessa forma, a ambiguidade do discurso de cidadania é visualizada ora pelo aspecto conservador que assume, ora pela potência emancipatória que cria fissuras no sistema oficial. Os limites desse conceito, portanto, refletem os limites do próprio Direito.

No ano de 1972, o professor Roberto Lyra Filho publica o livro "Criminologia dialética" que o tornou conhecido internacionalmente. Nesta obra, ele demonstra que a vertente do positivismo naturalista é um resultado histórico-ideológico da burguesia ascendente. Diametralmente a esta corrente, Lyra Filho escolhe o método dialético marxiano o que possibilita construir uma nova definição de direito e uma asseverada crítica ao jusnaturalismo e positivismo jurídico. Para ele, "o erro está justamente em ver todo o direito enquanto direito estatal [...]. Tal concepção mutiladora não explicaria o direito de contestação e libertação, o inconformismo positivo que se apresenta como direito também" (LYRA FILHO, 1972, p. 97).

A relevância desta interpretação é demonstrar que existem outras subculturas para além da cultura estereotipada da modernidade eurocêntrica. Nessa perspectiva, o direito não se resume à produção de normas Estatais, assim como, o cidadão não se reduz à figura estanque de 
eleitor. A visão de Roberto Lyra Filho é contrahegemônica, pois sugere que o "direito é processo, dentro do processo histórico: não é uma coisa feita, perfeita e acabada; é aquele vir-a-ser que se enriquece nos movimentos de libertação das classes e grupos [...]" (LYRA FILHO, 1999, p. 86). Logo, seria um equívoco afirmar que o direito é exclusivamente um instrumento de dominação social, pois através da cidadania e dos direitos humanos existe um espaço de luta e compensação de danos.

\section{CONCLUSÃO}

O conceito de cidadania é um pilar do direito moderno. A temporalidade histórica deste conceito lança luz sobre as matrizes ideológicas que fundamentavam sua existência nas Declarações do século XIX. O artigo comprovou sua hipótese ao demonstrar que os fundamentos da crítica de Marx ao conceito jurídico-formal de cidadania ainda permanecem válidas. Primeiro, porque a disparidade ontológica entre capital e trabalho não foi superada pelo capitalismo financeiro. Segundo, porque a nova roupagem do conceito de cidadania na pós-modernidade não ficou dissociada ao status formal de participação política e do monopólio legiferante do Estado

\section{REFERÊNCIAS}

ALVES, Alaôr Caffé. Função Ideológica do Direito. In: Diretório Acadêmico João Mendes Junior (Org.). Fronteiras do Direito Contemporâneo. São Paulo: Faculdade de Direito da Universidade Mackenzie, 2002.

ANDRADE, Vera Regina Pereira de. Sistema penal máximo x cidadania mínima. Códigos de violência na era da globalização. Porto Alegre: Livraria do Advogado, 2003.

. Cidadania: do direito aos direitos humanos. São Paulo: Acadêmica, 1993.

BELLO, Enzo. A cidadania na luta política dos movimentos sociais urbanos. Caxias do Sul: EDUCS, 2013.

COELHO, Lígia Martha C. Sobre o conceito de cidadania: uma crítica a Marshall, uma atitude antropofágica. In: COELHO, Lígia Martha C. et al. Cidadania/Emancipação. Rio de Janeiro: Tempo Brasileiro, 1990.

DERRIDA, Jacques. Força de Lei: o fundamento místico da autoridade. Trad. Leyla Perrone-Moisés. 2. ed. São Paulo: Editora WMF Martins Fontes, 2010.

DOUZINAS, Costas. O fim dos direitos humanos. São Leopoldo: Unisinos, 2009.

GROSSI, Paolo. O ponto e a linha. História do Direito e Direito Positivo na formação do jurista do nosso tempo. Revista Sequencia, Florianópolis/SC, vol. 26, n. 51, p. 31-45, dez. 2005.

LYRA FILHO, Roberto. O que é Direito. 17. ed. São Paulo: Brasiliense, 1999. 
LÖWY, Michael. Ideologias e ciência social: elementos para uma análise marxista. 19. ed. São Paulo: Cortez, 2010.

MARX, Karl. Crítica à filosofia de direito de Hegel. Tradução Rubens Enderle e Leonardo de Deus, $1^{\text {a }}$ ed. São Paulo: Editora Boitempo, 2005.

. Sobre a questão judaica. Tradução Daniel Bensaïd e Wanda Caldeira Brant. São Paulo: Boitempo, 2010.

. O Capital. v. 1. Rio de Janeiro: Civilização Brasileira, 2008.

. Manuscritos econômico-filosóficos. São Paulo: Boitempo, 2004.

ENGELS, F. A situação da classe trabalhadora na Inglaterra. São Paulo: Boitempo, 2008.

LAFARGUE, Paul. O Direito à Preguiça. São Paulo: Editora Claridade, 2003.

MARSHALL, Tomas Hamprey A. Cidadania, classe social e status. Tradução Merton Porto Gadelha. Rio de Janeiro: Zahar, 1977.

MENEGAT, Marildo. A face e a máscara: a barbárie da civilização burguesa. Pegada (UNESP), v. 8, p. 27-46, 2007.

NETTO, J. P. Crise do capital e consequências societárias. Serviço Social \& Sociedade, São Paulo, Cortez, n. 111, p. 413-429. jul./set., 2012.

. Marxismo impenitente: contribuição à história das ideias marxistas. São Paulo: Cortez, 2004.

SARTRE, Jean Paul. Questions de méthode: marxime et existencialisme. Critique de la raison dialethique. Paris: Gallimard, 1972.

SANTOS, Boaventura de Sousa. Os direitos humanos na pós-modernidade. Direito e sociedade. Coimbra, n. 4, p. 3-12, mar. 1989.

. Pela mão de Alice. O social e o político na pós-modernidade. São Paulo: Cortez, 1995.

. As dores do pós-colonialismo. Folha de S. Paulo. 21 ago. 2006.

THERBORN, Göran. A crise e o futuro do capitalismo In: SADER, Emir; GENTILI, Pablo (Orgs.). Pós-neoliberalismos: as políticas sociais e o Estado democrático. 6. ed. São Paulo: Paz e Terra.

TONET, I. Educar para a cidadania ou para a liberdade? Perspectiva, Florianópolis, v. 23, p. 469484, 2005.

VIEIRA, Liszt. Entre a terra e o céu: a cidadania do nacional ao global. In: ANNONI, Danielle (Org.) Os novos conceitos do novo direito Internacional. Cidadania Democracia e Direitos Humanos. Rio de Janeiro: América Jurídica, 2002. 
WARAT, Luis Alberto. A Rua Grita Dionísio! Direitos Humanos da Alteridade, Surrealismo e Cartografia. Tradução e Organização de Vivian Alves, Júlio Cesar e Alexandre Morais. Rio de Janeiro: Editora Lumem Juris, 2010.

WOLKMER, Antonio Carlos. Marx, A Questão Judaica e os Direitos Humanos. Revista Seqüência, Florianópolis, v. 48, n.48, p. 11-28, 2004.

. Introdução aos Fundamentos de uma Teoria Geral dos "Novos" Direitos. In: Os novos direitos no Brasil. São Paulo: Saraiva, 2012.

ZIZEK, Slavoj. O ano em que sonhamos perigosamente. Trad. Rogério Bettoni. 1. ed. São Paulo: Boitempo, 2012.

Recebido em: 09/07/2018 Aceito em: 27/11/2018 
